\title{
Public Survey Instruments for Business Administration Using Social Network Analysis and Big Data
}

\footnotetext{
Submitted 27/01/20, 1st revision 20/02/20, 2nd revision 15/03/20, accepted 03/04/20

V.V. Kolmakov ${ }^{1}$, L.N. Rudneva ${ }^{2}$, Y.E. Thalassinos ${ }^{3}$

Abstract:

Purpose: The subject matter of this research is closely intertwined with the scientific discussion about the necessity of developing and implementing practice-oriented means of measuring social well-being taking into account the intensity of contacts between individuals. The aim of the research is to test the toolkit for analyzing social networks and to develop a research algorithm to identify sources of consolidation of public opinion and key agents of influence. The research methodology is based on postulates of sociology, graph theory, social network analysis and cluster analysis.

Design/Methodology/Approach: The basis for the empirical research was provided by the data representing the reflection of social media users on the existing image of Russia and its activities in the Arctic, chosen as a model case.

Findings: The algorithm allows to estimate the density and intensity of connections between actors, to trace the main channels of formation of public opinion and key agents of influence, to identify implicit patterns and trends, to relate information flows and events with current information causes and news stories for the subsequent formation of a "cleansed" image of the object under study and the key actors with whom this object is associated.

Practical Implications: The work contributes to filling the existing gap in the scientific literature, caused by insufficient elaboration of the issues of applying the social network analysis to solve sociological problems.

Originality/Value: The work contributes to filling the existing gap in the scientific literature formed as a result of insufficient development of practical issues of using analysis of social networks to solve sociological problems.
}

Keywords: Sociological research, public opinion, big data, social space, social networks.

JEL classification: C83, M10.

Paper Type: Research article.

\section{Acknoledgements:}

* The authors would like to thank G.V. Dobromelov, Y.V. Zvorykina and M.Y. Turuntseva for their assistance and consulting support in defining the associative image of Russia in the Arctic.

\footnotetext{
${ }^{1}$ PhD (Econ.), Associate Professor, Plekhanov Russian University of Economics, Moscow, e-mail: vladimirkolmakov@mail.ru

${ }^{2}$ Doctor of Economic Sciences, Professor, Industrial University of Tyumen, Tyumen, e-mail: rudnevaln@mail.ru

${ }^{3} \mathrm{PhD}$ (Econ.), Adjunct Lecturer, Gulf University for Science and Technology, Kuwait, e-mail: thalassinos@hotmail.com
} 


\section{Introduction}

The sociological studies of public opinion, which have been spreading in recent decades, are increasingly focused on the search for solutions that combine widely described methods of traditional analysis with experimental methods of analysis of social space. This allows to obtain estimates of public opinion, less colored by subjectivism, because the individuals studied in this way, do not know about the fixation of their opinions, and therefore behave accordingly. One of the possible techniques for analyzing social space by revealing a set of its features is presented by the method of social network analysis. In particular, the theoretical possibilities of integrating spatial analysis and social network analysis are described by Adams et al. (2012). The practical implementation of this technique became possible relatively recently, as its application requires the use of specific software algorithms for collecting and processing sets of big data sourced from social networks as a means of quasi-public communication (Polyakova et al., 2019).

The work contributes to filling the existing gap in the scientific literature formed as a result of insufficient development of practical issues of using analysis of social networks to solve sociological problems, while theoretical works describing the theory and methodology of such analysis have been widely reflected in the scientific literature.

The research, is aimed at solving a specific practical problem and to answer the question whether building and assessing network links based on big data from quasipublic communication could become a tool for creating systems for monitoring social well-being and regular assessment of public opinion. It is reasonable to rely on big data to study public opinion, monitor social well-being and make decisions based on it. There are several reasons for this as:

1. Existing extrapolation forecast tools do not ensure proper quality of prediction and analytics (even nonlinear models). Social compresses, amplitude of fluctuations increases, causes and effects are distributed unevenly. At the same time, there is an exponential increase in economic instability. In practical terms, this leads to the fact that the patterns of the past do not always apply to the future, which makes us turn to new tools in forecasting, namely network models based on BigData principles.

2. Predictive models are based on irrelevant interdependencies. New factors are constantly appearing. Classical predictive models based on cause-and-effect algorithms do not take into account "Taleb's black swans", and "classical" sociology does not always allow revealing in a prompt mode of public reaction with full coverage of respondents online (the latter requires direct contact with the respondent for "reading" the data, which in case of network technologies is not required). Standard polling methods of studying public opinion lose their legitimacy due to the limitations described above. 
3. Unsatisfactory information supply in the form of:

- official statistics are lagging behind and the set of indicators is limited. In contrast, in the case of network analysis the data are accessed online, while the choice of indicators is not limited and is not dependent on the Federal State Statistics Service;

- the volume of information is growing exponentially and, consequently, the share of the Federal State Statistics Service's coverage is catastrophically decreasing;

- the frequency of measurement of indicators is unsatisfactory;

- there is no possibility of data verification.

Thus, the use of BigData allows us to go beyond the data set of Rosstat, the information is not delayed (online work) and allows us to make decisions on $100 \%$ sample coverage (as opposed to field sociology). Moreover, the built networks are a model of real social and economic processes, i.e. actually a more accurate model of society, suitable for decision-making (Thalassinos et al., 2019).

Traditional approaches to data analysis have been rendered unreliable precisely because of the excess of information considered, which either objectively or implicitly influences decision-making or behaviour choices (Thalassinos et al., 2009; 2012; 2013; Brandt et al., 2009; Hanias et al., 2007). The need to take into account the repeatedly increasing amount of information on social well-being in the process of goal-setting or planning seems to be logical, but the tools available today for working with BigData are far from the desired operationality, and therefore the niche of unmet demand continues to expand.

The development of the problem can be found in O'Sullivan (2014) work, where based on empirical data the possibility of applying key concepts and definitions from graph theory in sociological studies is justified. The use of the network approach in solving problems of sustainable development can be no less productive, contributing to the development of an integrated approach to the formation of a common socioeconomic space. In addition, works aimed at studying the interconnectedness of socio-economic space began to appear.

The object of this research is the methods of analysis of social networks, which we study for the possibility of their practical application for the needs of sociological study of public opinion. The aim of the study is to test the tools of social network analysis as applied to the study of public opinion and to develop a research algorithm to identify sources of consolidation of public opinion and key agents of influence. The image of Russia in the Arctic region as an atypical subject of public opinion research will be used as a case study.

\section{Problem Setting and Background Data}

The goal has been achieved in several research stages: 
1. Search and selection of associations "capturing" the semantic core of the Russian image in the Arctic.

2. Building and assessing social networks, including building the architecture of existing links.

3. Identifying key actors - agents of influence in the built network or opinion leaders - in relation to the image of Russia in the Arctic. This task has a variety of solutions developed in sociology, economics, linguistics, and other fields of knowledge. However, the most rational method has been proposed by Sengupta and the co-authors, who have developed and described a method for formalizing actor-to-actor relationships based on the characteristics of these relationships (Sengupta et al., 2015). From earlier works (Farrugia and Quigley, 2010), which investigated a number of ways to build networks of interaction between actors and described approaches to identifying opinion leaders, deserves attention.

4. Verification of pre-existing hypotheses with respect to influence agents.

The formed research algorithm allowed to search for hidden patterns and trends of public opinion, to correlate information flows and events with information causes and news stories for further formation of a "purified" idea of public opinion about Russia and its activities in the Arctic, and the key actors who promote this opinion.

While testing the toolkit, practical implementation of the BigData principles was provided by the resources of the microblogging service Twitter, records were selected by phraseological units. The nodes of the column were the Twitter service users, who in their messages mentioned in the specified period key phrases in any context (the public opinion translators). The technology of network analysis, in addition to traditional frequency indicators, based on the study of centrality allows to identify key actors to promote information and discussion areas with their specific content.

The investigated set was represented by all the actors, who are involved in expressing themselves in relation to the investigated problem. It is a global segment, geographically represented by any country, but limited to an English-speaking audience. The choice of this segment is based on the status of English as an international language for greater representativeness.

\section{Research Methods and Instruments}

The social network analysis is a modern direction of sociological research, which implies building a graph of relations between individuals on the basis of their expressed identity on a certain issue. In this graph, the nodes are represented by the participants in communication and the edges by the links between them. The evaluation of the schemes of discourse network organization allows not only to describe the nature of relations between communication participants, but also to estimate the strength of connections. The analysis of social networks originates in 
graph theory, the origins of which in the mathematical sciences were laid down by L. Euler in the 18th century, but as a method of research it became widespread only from the middle of the last century thanks to the studies of Fienberg, Meyer and Wassermann (1985) as well as Granovetter (2005).

Network analysis is applicable for building diagnostic monitoring systems or revealing hidden dependencies, which is well illustrated by the theory of "six handshakes" - the experiment of Milgram (1963 and 1974), according to which any two people on Earth are separated by no more than five levels of common acquaintances (and, accordingly, six levels of relationships). With regard to the study of social space and monitoring of social feelings, the social network analysis can be useful in that the generalizations of properties are made by the actors themselves - participants in social communications, where both separate information messages and word combinations can act as units, serving as means of expression of the studied problem, containing its characteristic features.

Social network analysis can be used as a tool for content analysis of media and blogs on the popularity of ideas, concepts and images, as well as to identify distribution channels. In modern domestic and foreign literature, including publicist and business journalism, building and visualizing networks is a fairly common phenomenon, which, however, does not fully reveal the analytical and search capabilities of social network analysis. The beauty of the tool is that it can be applied to large amounts of data, manual processing of which seems to be a very labor-intensive process, and automated - through self-learning linguistic mechanisms - is cost-intensive in terms of necessary resources. At the same time, social network analysis eliminates the need for the analyst to go through all the records, drawing his attention only to the key nodes and connections that form the subject of his research interest.

The methodology of this research was previously described in Kolmakov, Polyakova and Polyakov (2019) and Polyakova et al. (2019) regarding the approach to data consolidation and instruments employed. At the first research stage, in order to identify opinion leaders, study the architecture of their links and make managerial decisions about the need for corrective action or lack thereof, it is necessary to identify a list of key words or phrases that can become markers of further search and outline the framework of the investigated problem. To assess the image of Russia in the Arctic, a set of 50 key words or phrases, presumably characterizing the international perception of Russia and its activities in this region, was formed by experts ${ }^{4}$.

In order to form a more adequate and representative sample, the semantic field was verified by comparing the selected key phrases with the characteristics of the

\footnotetext{
${ }^{4}$ The experts were specialists working in depth on issues related to the development of the Arctic.
} 
contemporary scientific and network discourse, i.e. to answer the following questions:

$\checkmark$ Are the terms proposed by specialists really capable of comprehensively describing this problem?

$\checkmark$ Do they outline the current image fairly accurately or is there a discrepancy between the experts' opinion and the real situation?

$\checkmark$ Is the sample received from experts a projection of their subjective opinion on the required state of the information field?

The latter question should be evaluated as a principal one, since it is very likely that the experts' opinion takes into account the time factor and the totality of their target goals, therefore, the set of phrases proposed by them may describe not the current but the expected state and their predictive perception.

Regarding the above-mentioned problems of information gathering, a chain of associations characterizing the current state of Russia's image in the Arctic was identified. The study of links through a set of associations will make it possible, passing through several nodes, to reach a "cloud" describing the totality of problems.

However, it is quite wrong to assume that these links form the semantic core of the Russian image in the Arctic. The analysis of search engine statistics on the keyword of interest, its derivatives, and associations showed the frequency of queries for the terms under study. Thus, the maximum number of search queries (as of March 2018, the depth of search - five days) is found for the word combination "arctic circle" (90.5 thousand times). This query is not the most popular. For comparison, the word "Putin" is found 1.22 million times, i.e. approximately 12 times more frequently, "Trump" - 20.4 million times, "Russia" - 2.24 million times, and Star Wars - 11.1 million times.

Three terms are basic: "arctic circle", "arctic ocean", "arctic zone". In aggregate, the queries with the word "arctic" are met 201 thousand times. This word is excluded from the descriptive statistics, because all search queries related to it, give the whole set of possible combinations, including "arctic circle", "arctic ocean", etc. Most associate pairs are not reflected in the statistics of search queries at all. In this case, the interests of the Russian-speaking and English-speaking audiences are different in terms of both the number of queries and the popularity of individual word combinations with the word "Arctic". Thus, even a superficial assessment of perception showed that there is no association of keywords with image formation among users. However, this dissonance is not an obstacle to network building as it does not exclude the possibility of reaching user groups through several intermediate nodes.

A dataset was collected, represented by various actors who mentioned one of 50 words or their word forms. The content analysis of the sample pointed to the need to 
censor the sample by deleting messages containing their own and non-negative names, including trademarks and species names: "Arctic monkeys" - music band, "Arctic cat" - snowmobile model, "arctic bear" - polar bear, "arctic fox" - fox, "Arctic" as an alias or part of a human nickname. All these cases had no direct relation to the investigated problem and could significantly distort the results of the analysis. There are 3642 messages left after the filtering. The research algorithm used below included the following:

1. Collecting data from social media via a list of keywords and word combinations.

1.1 Linking input data in a dataset.

1.2 Verification, integrity verification and censoring of data (elimination of repetitions).

1.3 Unloading data into a machine-readable format that allows processing by specialized DBMS software and hardware complexes and social network analysis.

2. Forming a dataset based on database loading into a software.

3. Network building and identification of actors, including the key ones.

4. Determination of "centers of influence": analysis of network metrics - forces of connections and centrality.

5.Visualization of data structure, architecture of social connections of key actors using infographics.

6. Building subgraphs of individual actors.

7. Search for effective channels for promoting information, clusters within the network.

Performed visualization of the network of actors' interactions built by the keyword "Arctic" in Figure 1, has a total of more than 4000 nodes. Preemptively, it should be noted that all actors and their messages have identification. Their specific addresses and messages are not shown in the Figure (only visual limitation) but are contained in the database and each of them can be identified if necessary.

Figure 1. Network visualization of the dataset in unstructured (left) and structured (right) form
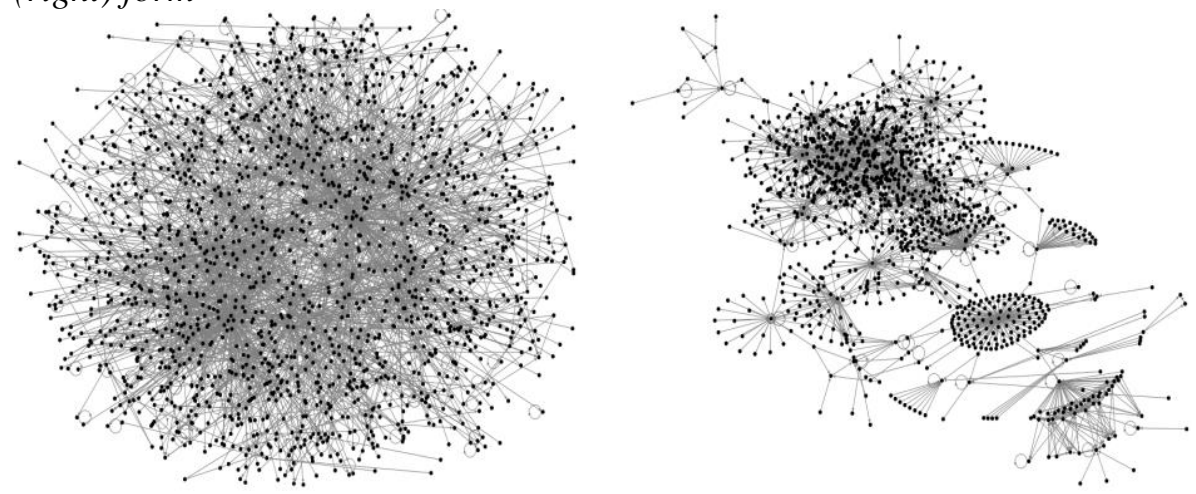

Source: Authors' calculations. 
Obviously, without structuring by means of specialized algorithms, the presented network gives limited possibilities for interpretation of its links and selection of more or less homogeneous groups of actors, and as a result of structuring, groups of actors forming some form of clusters become evident.

The use of clustering algorithms allows to establish that in the studied dataset there are more than 40 clusters, the largest of which are represented by many actors and connections between them. According to Stark (2016), the density of individual parts of the network allows to provide an acceleration of information transfer of a given tonality due to intragroup relations, resulting, for example, in "imposing" the opinion of one actor of the whole set of actors, whose identity with this group is beyond doubt (Stark, 2016). The most representative are clusters 1 (in the center of Figure 2), cluster 2 (at the top of Figure 3 below) and cluster 4 (at the bottom of Figure 3).

Figure 2. Results of clustering the public communication network with reference to the Arctic in any context

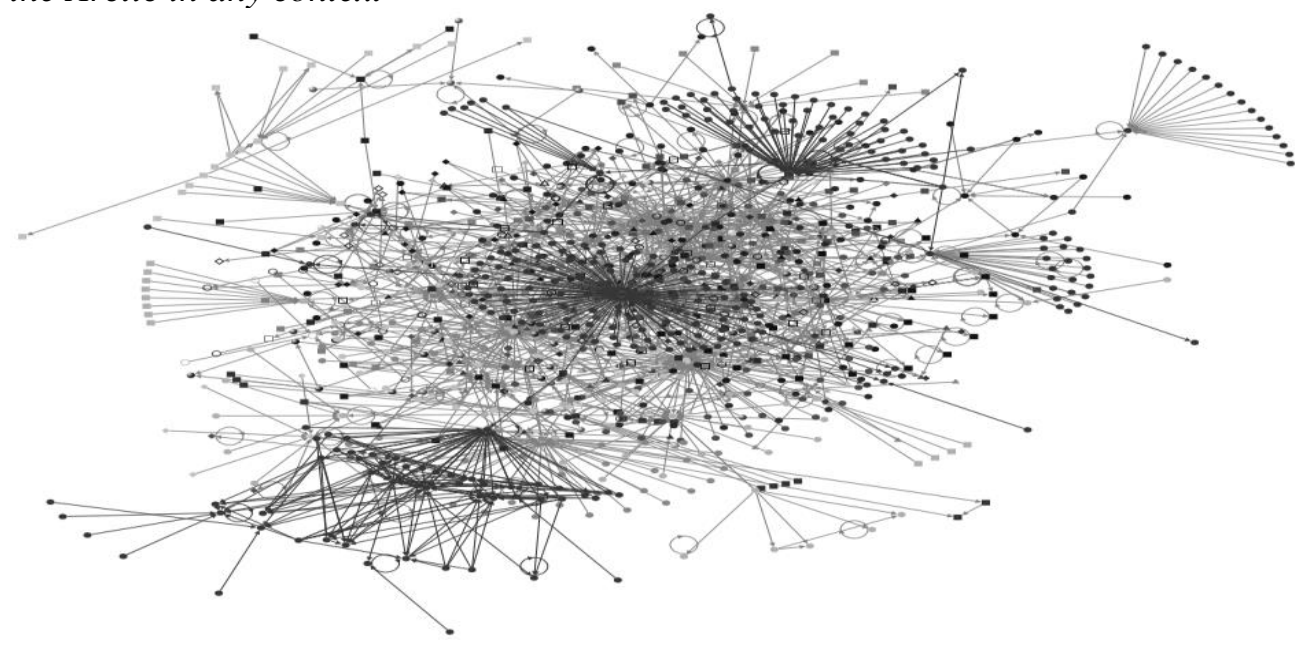

Source: Authors' calculations.

Clusters 1 and 2 have a common denominator related to global warming and Arctic ice conservation. In particular, the first cluster is represented by the message of the United Nations Environment Programme and the social activity unfolding around it: "Arctic sea ice may vanish during the summer this century even if \#ParisAgreement target is met - scientists". It is this message and the reactions of users to it - the further spread of the message through its subnetwork - that form the most significant information impulse in the generated data set for the time period in question.

Cluster 4 is also close to environmental issues, but it has initiated discussions on a possible ban on hydrocarbon development in Arctic Norway. It should be noted that the division of actors into clusters does not mean "uniqueness" of the subject matter of their discussion. For example, the climate and environmental themes are predominant in the context of the references to the word "Arctic" in the English- 
speaking Twitter segment. Other contexts include Arctic flora and fauna reflected in photocollections. The Arctic as a place of action of the geopolitical struggle is considered by very few actors consolidated around the confrontation with the incumbent US President D. Trump. Among the ten actors with the highest popularity index (in-degree) no politically oriented actors are presented in Table 1:

Table 1. Characteristics of the most popular actors in the formed sample

\begin{tabular}{|c|c|c|c|c|c|c|}
\hline \multicolumn{2}{|l|}{ Actor } & \multirow{2}{*}{$\begin{array}{l}\text { Actor } \\
\text { type* }\end{array}$} & \multirow{2}{*}{$\begin{array}{l}\text { In- } \\
\text { degree }\end{array}$} & \multirow{2}{*}{$\begin{array}{l}\text { Prevailing topics } \\
\text { for entries }\end{array}$} & \multicolumn{2}{|l|}{ Quantity } \\
\hline & & & & & Followers & Entries \\
\hline$@$ unep & $\begin{array}{l}\text { UN Environment } \\
\text { Program }\end{array}$ & Org. & 116 & Climate & 604000 & 21300 \\
\hline @awwcuteness & Aww Cuteness & Org. & 59 & Photo of animals & 332000 & 23300 \\
\hline @ climatecentral & Climate Central & Org. & 54 & Climate & 60600 & 46800 \\
\hline @mwobs & \begin{tabular}{|l} 
Mount \\
Washington \\
Observatory \\
\end{tabular} & Org. & 52 & Climate & 9205 & 1851 \\
\hline @ bendahanl & Luci & Ind. & 39 & $\begin{array}{l}\text { Photos of nature, } \\
\text { including the } \\
\text { Arctic. }\end{array}$ & 42600 & 119 \\
\hline @ mjventrice & Michael Ventrice & Ind. & 38 & Meteorology & 10700 & 11500 \\
\hline @foeeurope & \begin{tabular}{|l|} 
Friends of the \\
Earth \\
\end{tabular} & Org. & 34 & \begin{tabular}{|l|} 
Environmental \\
Protection
\end{tabular} & 24900 & 7070 \\
\hline @crystal_fishy & Crystal Fish & Ind. & 34 & Photo of animals & 37100 & 364000 \\
\hline @ travelinglens & Vivienne Gucwa & Ind. & 28 & Nature Photos & 47900 & 16500 \\
\hline$@$ unfccc & $\begin{array}{l}\text { United Nations } \\
\text { climate change } \\
\text { secretariat }\end{array}$ & Org. & 26 & Climate & 368000 & 19000 \\
\hline
\end{tabular}

Note: "org." - collective actor (e.g. organization), "ind." - individual actor

Source: Authors' calculations.

The resulting network may describe the size of the current information field in relation to the Arctic, but poorly reflects the attitude towards Russia within this issue. It shows an attitude toward the Arctic as such, but not toward Russia's role in its development. In order to obtain more representative results for the purpose of the study, the original sample was filtered out: only messages that included the word "Russia" and its derivatives were saved from the total dataset. From the set of 3642 messages 51 messages remained. Thus, only $1.4 \%$ of the entries related to the "Arctic theme" are associated with the mention of the word "Russia" and its derivatives.

Most likely, an average Twitter user living in the UK, for example, does not have his own understanding of Russia's policy in the Arctic region. Most likely, this user retransmits the image transmitted to him by mass media in one of the following ways: 
$\checkmark$ posting the message on its page ("retweet"), i.e. distributes it further through their network of contacts;

$\checkmark$ expresses emotional coloration, i.e. "like";

$\checkmark$ analyses and expresses a meaningful attitude, i.e. critically agrees or disagrees with the author of the article.

Consequently, the primary source and further object of influence on public opinion from the Russian side may be the "sources" of public opinion and the key actors who ensured its spread. In order to identify the architecture of links, a network of actors was built that placed or responded to relevant messages ("likes", "comment", "retweet"). The visual representation of the network is shown in Figure 3:

Figure 3. Links between actors who used or "liked" posts containing the word "agents" and related to the "Russian" subject (English Twitter segment)

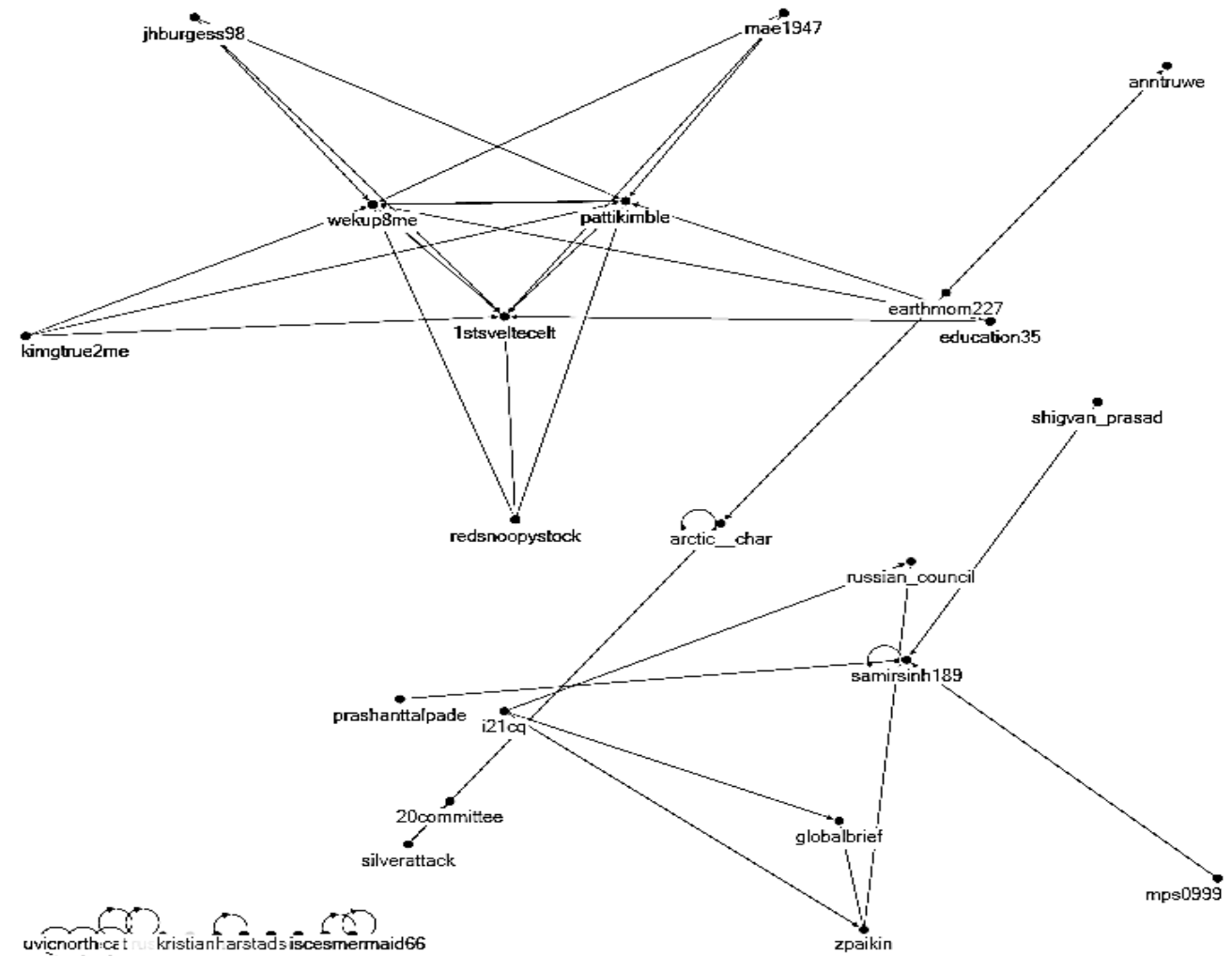

This Figure is a network with an emphasis on clusters, as it highlights the most connected groups of actors. The analysis of the sample shows the absence of significant "centers of influence", indicates that the information space is discrete and does not show signs of consolidation. Studies conducted earlier on other issues, allow us to argue that such an architecture is observed in poorly or inefficiently managed information systems, in which the policy vector of the concerned subject is not clearly marked. 


\section{Results and Discussion}

Let's take a closer look at the actors and their information messages, as well as information motives that gave rise to the network. The most expressive cluster, represented as a pentagram with a triune center, is formed by a single message "So. Exxon probably promises to pay royalties to Russia for Arctic drilling after sanctions end" - and its further promotion by three key (for this subnet) actors, uniting the beginning of which is the criticism of the policy of D. Trump:

$\checkmark$ Patti Kimble (@PattiKimble; 12.1 thousand subscribers). Prevailing content - reports on domestic political initiatives in the USA, moderate opposition of D. Trump.

$\checkmark$ Slàinte (@1stSvelteCelt; 1712 subscribers). Prevailing content - criticism of D. Trump and his policy.

$\checkmark$ Wendy K8 Moments (@Wekup8me; 92 subscribers) - Prevailing content reports on domestic political initiatives in the USA, moderate opposition of D. Trump.

The distribution of 51 network edges by context is as follows:

$\checkmark 29$ edges - Criticism of D. Trump, including for the alleged connection with Russia (the Arctic is mentioned as Exxon's place of action in the Russian part of the Arctic shelf);

$\checkmark 6$ edges - "arms race" of Russia and the US in the Arctic (in the context of the US lagging behind and, again, criticisms of D. Trump);

$\checkmark \quad 5$ edges - Environmental problems in the Arctic (Russia is mentioned among others who are called upon to intervene);

$\checkmark 5$ edges - discussion of the Arctic Union (an inter-ethnic organization), of which Russia is a member;

$\checkmark \quad 3$ edges - discussion of the Russian North and its culture (ethnocultural context, positively colored).

Thus, in the English-speaking segment of Twitter, Russia in the context of the Arctic is most often mentioned as an argument in the political struggle to overthrow D. Trump, as well as in criticism of his policy, including personnel decisions: there is an allusion to the achievements of R. Tillerson (former head of Exxon, in the recent past - U.S. Secretary of State) in interaction with Russia. Consequently, the current discourse on the Arctic and Russia at the time of the study contained two key points:

$\checkmark$ Exxon is going back to developing Russian oil and gas fields;

$\checkmark$ Trump's initiatives are assessed in connection with the possible personal benefits for him and R. Tillerson and the necessary sanctions lifting.

Based on the above, we can state that the discussion is taking place around the Russian Arctic shelf as a "place of economic activity", and from the position of 
domestic political struggle in the United States. At the same time, the capacity of the network is insignificant, though the reason for the latter may be technical limitations of the sample (there were no significant media reasons for this during the research period).

Table 2 shows specific quantitative parameters, identifying actors and their information messages. The choice of actors is based on two characteristics - indegree and out-degree. The first one represents a measure of the number of incoming connections, i.e. the absolute popularity of the actor, and the second one represents the number of outgoing connections, i.e. the measure of the actor's activity.

Table 2. Characteristics of actors (opinion leaders) and their information messages

\begin{tabular}{|c|c|c|c|c|}
\hline Actor name & Contents of post & $\begin{array}{l}\text { Number of } \\
\text { subscriber } \\
\text { s }\end{array}$ & $\begin{array}{l}\text { Number of } \\
\text { actor } \\
\text { recordings }\end{array}$ & $\begin{array}{l}\text { Number of } \\
\text { connection } \\
\text { s }\end{array}$ \\
\hline \multicolumn{5}{|c|}{ Actors with the highest In-degree value (incoming links) } \\
\hline $\begin{array}{l}\text { Slàinte } \\
\text { (@ 1stSvelteCelt) }\end{array}$ & \multirow{3}{*}{$\begin{array}{l}\text { So. Exxon possibly promises to pay } \\
\text { royalties to Russia for Arctic Drillings after } \\
\text { sanctions end }\end{array}$} & 1712 & 34200 & 7 \\
\hline $\begin{array}{l}\text { Patti Kimble } \\
\text { (@PattiKimble) }\end{array}$ & & 12100 & 118000 & 6 \\
\hline $\begin{array}{l}\text { Wendy K8 } \\
\text { Moments } \\
\text { (@Wekup8me) }\end{array}$ & & 92 & 2806 & 6 \\
\hline $\begin{array}{l}\text { Samir Dattopadhye } \\
\text { @ samirsinh189 }\end{array}$ & $\begin{array}{l}\text { In reply to Russia's \#Arctic might USA } \\
\text { conducts \#MilitaryDrills even in }-60^{\circ} \mathrm{C} \text {. } \\
\text { Energy \& resource-rich Poles could be } \\
\text { \#NewAge conflict zones. }\end{array}$ & 4634 & 1556 & 4 \\
\hline \multicolumn{5}{|c|}{ Actors with the highest Out-degree (outbound) value } \\
\hline $\begin{array}{l}\text { John Burgess } \\
\text { (@jhburgess98) }\end{array}$ & \multirow{3}{*}{$\begin{array}{l}\text { So. Exxon possibly promises to pay } \\
\text { royalties to Russia for Arctic Drillings after } \\
\text { sanctions end }\end{array}$} & 4994 & 18800 & 3 \\
\hline $\begin{array}{l}\text { Demi Crat } \\
\text { (@ redsnoopystock) }\end{array}$ & & 569 & 47800 & 3 \\
\hline $\begin{array}{l}\text { bob sondag } \\
(@ \text { Education35) }\end{array}$ & & 66 & 4997 & 3 \\
\hline
\end{tabular}

Source: Authors' calculations.

The revealed structure of the information space does not allow to state that there are signs of a systemically conducted policy, since in the network discourse mentioned above Russia's activity in the Arctic is mentioned only in the application to the problems of the American establishment, broadcasting previously formed stereotypes concerning Russia in general: sanctions, arms race, etc.

That is, Russia's activities in the Arctic are not directly the subject of interest or discussion, but serve as a concept through the prism of which internal American issues related to, among other things, political struggle against the background of the 2016 U.S. presidential elections and subsequent protests are analyzed and criticized. 


\section{Future Research Opportunities}

During the analysis of public opinion on a given model case (Russia's activity in the Arctic) in the reflection of social networks, it was found that the experimental method used makes it possible to obtain actual results that allow to track the dynamics of the problem field in the most mobile environment - the Internet.

One of the promising applications for the results of this research can be segmentation of the information field by obvious criteria (geography, age, etc.) or non-obvious criteria (models of information dissemination, key actors and clusters, specifics of interests of the relevant group). For example, in the subsequent part of this research (not presented in the current article) it became obvious that the subjects forming and transmitting the image of a specific official - D. Rogozin - are "consistent critics" of the current American president, while the actual "antiRussian" sentiments for these actors are secondary. As a result of such discoveries, it may be possible to focus information support on Russia's activities in developing the Arctic region. This direction could be designated as the development of behavioral models capable of detecting implicit connections and motivation factors.

The study of individual subgraphs (networks within a network) may be in demand from the perspective of developing private lines of influence on some selected aspects of the problem in question. For example, studying the subgraph of a political leader would make it possible to form targeted recommendations for shaping "the right" public opinion.

The potential for BigData implementation and networking, for example in the public sector, is very significant. The explored and promising areas of application of the method include:

identifying agents of influence in social networks (in social systems - opinion leaders);

analysis of the effectiveness of information distribution channels; operational monitoring of public opinion on topical issues;

evaluation of transactions and other interactions between different actors;

modeling actor behavior, especially in response to introduction of innovations or any other incentives to increase productivity (Polyakova, Kolmakov and Yamova, 2019; Polyakova et al., 2018).

Other possible applications of BigData technology include the assessment of public opinion on the effectiveness of socio-economic policy measures. For example, there is a perception that mechanistic models aimed at improving the systems of state and municipal administration are inadequate in themselves, while the inclusion of elements of social network analysis provides an additional impetus for development through continuous innovation, which will become available as human and social capital is unlocked as in the work of Pepper and Sense (2014) and Halpern, Rozaidi 
and $\mathrm{Ki}$ (2012) who studied 160 websites from 82 countries, including the Arab world, and illustrated how they are used and delivered.

The technology of sociological research discussed in this article can also be used to track public opinion about the activities of public authorities and to influence the authorities to improve their effectiveness (Mentzer and Washington, 2015), as well as the controlled dissemination and suppression of rumors, especially those affecting the interests of the ruling class ( $\mathrm{Li}$ and $\mathrm{Ma}, 2017$ ). We see its considerable potential in the development of applied aspects of the concept of Internet-federalism (Kolmakov and Polyakov 2017), which involves the assessment of the consequences of the ousting of the authorities by their internet institutions, as described in (Halpern and Katz, 2012). The estimation of public opinion through the analysis of social networks can be useful in forecasting the results of electoral procedures (Tilton, 2008).

The formation of a complete picture of the standard of living and quality of life of the population is closely intertwined with questions of surveillance of citizens by the state and possible violation of the right to privacy, which is one of the threats to the spread of the method (Bedi, 2014). On the other hand, an analysis of sources shows that there are examples of quite peaceful use of data from social networks to form client-oriented models of territorial development based on the momentary response of the population. For example, the examples of Macao and Hong Kong describe a successful experience of using information about tourists to improve domestic policies aimed at making territories more attractive (Peipeng and Sim, 2014).

\section{References:}

Adams, J., Faust, K., Lovasi, G.S. 2012. Capturing context: Integrating spatial and social network analyses. Social Networks, 34(1), 1-5. DOI: 10.1016/j.socnet.2011.10.007

Bedi, M. 2014. Social networks, government surveillance, and the fourth amendment mosaic theory. Boston University Law Review, 94(6), 1809-1880.

Brandt, A., Hahn, C., Krätke, S., Kiese, M. 2009. Metropolitan regions in the knowledge economy: Network analysis as a strategic information tool. Tijdschrift Voor Economische En Sociale Geografie, 100(2), 236-249. DOI: 10.1111/j.14679663.2009.00532.x

Farrugia, M., Quigley, A. 2010. Actor Identification in Implicit Relational Data Sources. In: Ting, I.H., Wu, H.J., Ho, T.H. (eds) Mining and Analyzing Social Networks. Studies in Computational Intelligence, vol 288, 67-89, Springer, Berlin, Heidelberg. DOI: 10.1007/978-3-642-13422-7_5

Fienberg, S.E., Meyer, M.M., Wasserman, S.S. 1985. Statistical analysis of multiple sociometric relations. Journal of the American Statistical Association, 80(389), 5167. DOI: $10.1080 / 01621459.1985 .10477129$

Granovetter, M. 2005. The impact of social structure on economic outcomes. Journal of Economic Perspectives, 19(1), 33-50. DOI: 10.1257/0895330053147958.

Halpern, D., Katz, J.E. 2012. From e-government to social network government: Towards a transition model. 4th Annual ACM Web Science Conference, WebSci'12, 119-127. DOI: $10.1145 / 2380718.2380735$ 
Halpern, D., Rozaidi, N.A., Ki, S. 2012. Towards a social network e-government agenda? Measuring participation 2.0 in the Arab world. ACM International Conference Proceeding Series, 223-231. doi:10.1145/2307729.2307765.

Hanias, P.M., Curtis, G.P. and Thalassinos, E.J. 2007. Non-linear dynamics and chaos: The case of the price indicator at the Athens Stock Exchange. International Research Journal of Finance and Economics, 11(1), 154-163.

Kolmakov, V., Polyakov, S. 2017. Internet-federalism and its evidence in liberal forces consolidation in Russia. Federalism, 3, 7-18 (in Russian).

Kolmakov, V., Polyakova, A., Polyakov, S. 2019. A valuation approach to the Russian liberal establishment consolidation. Administratie Si Management Public, (32), 93107. doi:10.24818/amp/2019.32-07.

Li, D., Ma, J. 2017. How the government's punishment and individual's sensitivity affect the rumor spreading in online social networks. Physica A: Statistical Mechanics and its Applications, 469, 284-292. DOI: 10.1016/j.physa.

Mentzer, K.D., Washington, A. 2015. Understanding shifting dynamics of power in state governments through social networks. In 2015 Americas Conference on Information Systems, AMCIS 2015 Americas Conference on Information Systems.

Milgram, S. 1963. Behavioral Study of Obedience. Journal of Abnormal and Social Psychology, 67(4), 371-378.

Milgram, S. 1974. Obedience to Authority: An Experimental View. Harpercollins. ISBN 978-0-06-131983-9.

O’Sullivan, D. 2014. Spatial Network Analysis. In: Fischer, M., Nijkamp, P. (eds) Handbook of Regional Science, 1253-1273. Springer, Berlin, Heidelberg. doi:10.1007/978-3642-23430-9_67.

Peipeng, L., Sim, R.T.T. 2014. Research experience of big data analytics: the tools for government: a case using social network in mining preferences of tourists. In Proceedings of the 8th International Conference on Theory and Practice of Electronic Governance (ICEGOV '14). Association for Computing Machinery, New York, NY, USA, pp. 312-315. DOI: 10.1145/2691195.2691200.

Pepper, M., Sense, A.J. 2014. Local government service systems improvement:

Exposing the social networks. Journal of Management and Governance, 18(3), 873890. DOI: 10.1007/s10997-012-9255-0.

Polyakova, A., Kolmakov, V., Yamova, O. 2019. Regional competitiveness response to innovation changes: Issues of evaluation. Journal of Urban and Regional Analysis, 11(2), 159-172. doi:10.37043/JURA.2019.11.2.3.

Polyakova, A.G., Loginov, M.P., Serebrennikova, A.I., Thalassinos, E.I. 2019. Design of a socio-economic processes monitoring system based on network analysis and big data. International Journal of Economics \& Business Administration, 7(1), 130-139.

Sengupta, S., Das, I., Sarkar, R., Kolya, A.K. 2015. Event \& event actor identification with event-sentiment relation. 2015 IEEE International Conference on Research in Computational Intelligence and Communication Networks (ICRCICN), 423-428. DOI: 10.1109/ICRCICN.2015.7434276.

Stark, T.H. 2016. The density of social networks moderates effects of intergroup contact. International Journal of Intercultural Relations, 55, 133-147. DOI: 10.1016/j.ijintrel.2016.10.004.

Tilton, S. 2008. Virtual polling data: A social network analysis on a student government election. Webology, 5(4), Article 64. Available at: http://www.webology.org/2008/v5n4/a64.html.

Thalassinos, I.E., Hanias, P.M., Curtis, G.P. and Thalassinos, E.J. 2009. Chaos theory: 
Forecasting the freight rate of an oil tanker. International Journal of Computational Economics and Econometrics, 1(1), 76-88.

Thalassinos, I.E., Hanias, P.M. and Curtis, G.P. 2012. Time series prediction with neural networks for the Athens Stock Exchange indicator. European Research Studies Journal, 15(2), 23-31.

Thalassinos, I.E., Hanias, P.M., Curtis, G.P. and Thalassinos, E.J. 2013. Forecasting financial indices: The Baltic Dry Indices. Marine Navigation and Safety of Sea Transportation: STCW, Maritime Education and Training (MET), Human Resources and Crew Manning, Maritime Policy, Logistics and Economic Matters; Code 97318, 283-290, ISBN: 978-113800104-6.

Thalassinos, I.E., Cristea, M., Noja, G.G. 2019. Measuring active ageing within the European Union: Implications on economic development. Equilibrium, Quarterly Journal of Economics and Economic Policy, Vol. 14, Issue 4, 591-609. DOI:

10.24136/eq.2019.028. 